\title{
Effect of botanical composition of silages on rumen fatty acid metabolism and fatty acid composition in longissimus muscle and subcutaneous fat of lambs
}

\author{
M. Lourenço, S. De Smet, K. Raes ${ }^{\dagger}$ and V. Fievez ${ }^{\ddagger}$ \\ Laboratory for Animal Nutrition and Animal Product Quality, Department of Animal Production, Ghent University, Proefhoevestraat 10, 9090 Melle, Belgium
}

(Received 20 November 2006; Accepted 20 March 2007)

\begin{abstract}
To study the effect of feeding silages with different botanical composition, on rumen and lamb fat, 30 male lambs were assigned to five different silage groups for 11 weeks: botanically diverse silage (BDS); white clover silage (WCS); red clover silage (RCS), intensive English ryegrass silage (IRS) and crushed linseed and maize silage (MSL). Besides the silages, animals received organic wheat and barley and the MSL group additionally received bicarbonate (15 g/day). Silages were sampled when the bales were opened and analysed for fatty acid (FA) content and chemical composition. At slaughter, ruminal contents were sampled and $24 \mathrm{~h}$ after slaughter, longissimus muscle and subcutaneous (SC) fat were sampled. All samples were analysed for FA composition. The MSL group ingested the highest amount of FA (35.8 g/day v. 13.5, 19.4, 17.2 and 30.4 g/day for MSL v. $B D S, W C S, R C S$ and IRS, respectively) and the sum of the major polyunsaturated FA, C18:2 n-6 and C18:3n-3, was similar for groups BDS, WCS, RCS and MSL $(61.3 \mathrm{~g} / 100 \mathrm{~g}, 62.3 \mathrm{~g} / 100 \mathrm{~g}, 62.3 \mathrm{~g} / 100 \mathrm{~g}, 63.7 \mathrm{~g} / 100 \mathrm{~g}$ of FA methylesters (FAME), respectively), while group IRS ingested higher proportions of these FA (74.5 g/100 g of FAME). Rumen data showed that animals fed BDS presented higher proportions of biohydrogenation intermediates, particularly C18:1 111 and CLA C9t11, suggesting partial inhibition of rumen biohydrogenation. In the MSL group, the content of C18:3n-3 in the rumen was highest, most probably due to reduced lipolysis and hence biohydrogenation through the combined effect of esterified C18:3n-3 and seed protection. Additionally, C18:3 n-3 proportions were higher in rumen contents of RCS animals compared with WCS animals, which could be due to the activity of the polyphenol oxidase enzyme in the $R C$ silages. Proportions of C18:3n-3 were similar between treatments both for SC and intramuscular (IM) fat, whereas CLA C9t11 content was higher in the SC fat of BDS animals and lower in the IM fat of IRS animals compared with the other forage groups. No differences were found for C20:4 n-6, C20:5 $n-3, C 22: 5 n-3$ and C22:6 n-3 in the IM fat of the animals. Nevertheless, indices for desaturation and elongation activity in muscle of BDS animals suggest some stimulation of the first three steps of desaturation and elongation ( $\Delta 6$-desaturase, elongase and $\Delta 5$-desaturase) of long-chain FA.
\end{abstract}

Keywords: biohydrogenation, botanical composition, fatty acids, metabolism, silage

\section{Introduction}

Some recent studies have demonstrated that the botanical composition of grazed pastures affects the fatty acid (FA) profile of milk (Collomb et al., 2002; Žan et al., 2006) and meat (Ådnøy et al., 2005; Lourenço et al., 2007). Moreover, simultaneous determination of rumen, subcutaneous (SC) and intramuscular (IM) FA profiles revealed some of the changes in the tissue FA profile to be related to

\footnotetext{
${ }^{\dagger}$ Present address: EnBiChem, Department PIH, University College of WestFlanders, Graaf Karel de Goedelaan 5, 8500 Kortrijk, Belgium.

† E-mail: veerle.fievez@UGent.be
}

modifications of the rumen and tissue FA metabolism. Indeed, grazing a botanically diverse pasture compared with an intensive ryegrass pasture resulted in an accumulation of biohydrogenation intermediates in the rumen and in an increase of long-chain polyunsaturated FA (PUFA) in IM fat (Lourenço et al., 2007), suggesting a partial inhibition of rumen biohydrogenation and a stimulation of desaturation and elongation of PUFA. Within the same context, former work at our laboratory (Lourenço et al., 2005b) revealed higher milk conjugated linoleic acid (CLA) proportions when dairy cows were fed a mixture of silage richer in herb species than cows fed intensively managed ryegrass silage. Other studies (Dewhurst et al., 2003a and 
2003b; Lee et al., 2003) also reported a reduced rumen biohydrogenation of FA from clover-rich silages compared with other alfalfa and grass silages. Changes in rumen FA metabolism might be related to the presence of specific herbs in botanically diverse pastures, as they are reported to contain metabolites with antimicrobial properties (Wallace, 2004).

The effect of the botanical composition of silages on SC and IM FA composition has not been studied in depth. Thus, the objectives of this study were to describe the IM and SC FA composition in relation to (i) feeding intensive ryegrass $v$. clover $v$. botanically diverse silage (BDS); (ii) white $v$. red clover silage (RCS) feeding and (iii) C18:3 n-3 supply from forage silages $v$. linseed. Moreover, rumen FA composition and muscle FA indices were used to assess some indicators for rumen and muscle FA metabolism.

\section{Material and methods}

\section{Animals}

Thirty male lambs of similar genetic background ('Vlaams Kuddeschaap', a typical 'herding' sheep breed), born from yearling ewes and originating from an organic farm (Berendrecht, Belgium) were used. Before the beginning of the trial, lambs were grazing with their mothers on pastures of the organic farm of origin. At weaning, animals were assigned based on their live weight and age to one of the five different groups (six lambs per group), i.e. a group fed botanically diverse silage (BDS), white clover silage (WCS), red clover silage (RCS), intensive English ryegrass silage (IRS) or maize silage and crushed linseed (MSL). The average age and live weight at the onset of the experimental period was $118 \pm 8$ days and $29.6 \pm 3.6 \mathrm{~kg}$ respectively, and did not differ significantly between groups. Animals of the same group were divided into two pens (three animals per pen).

\section{Feeding and diets}

The experiment lasted 11 weeks (5 July 2005 until 19 September 2005). Animals were fed in the morning at $0800 \mathrm{~h}(700 \mathrm{~g} / \mathrm{kg}$ dry matter (DM) of silage and $300 \mathrm{~g} / \mathrm{kg}$ DM of a mixture of wheat and barley, separately). The amount of feed was adjusted per pen every 15 days to meet net energy (Voedereenheid Vleesproductie Intensief (VEVI), Van Es, 1978; Centraal Veevoederbureau (CVB), 2004) and protein (Darmverteerbaar Eiwit (DVE), Tamminga et al., 1994; CVB, 2004) requirements in accordance with the average growth rate of the three animals per pen. Essential minerals (sodium $(270 \mathrm{~g} / \mathrm{kg}$ ), calcium $(60 \mathrm{~g} / \mathrm{kg}$ ), phosphorus $(2 \mathrm{~g} / \mathrm{kg})$ and magnesium $(1 \mathrm{~g} / \mathrm{kg}))$ and micronutrients (zinc $(18000 \mathrm{mg} / \mathrm{kg})$, manganese $(2000 \mathrm{mg} / \mathrm{kg})$, iodine $(100 \mathrm{mg} /$ $\mathrm{kg})$, cobalt $(40 \mathrm{mg} / \mathrm{kg})$ and selenium $(10 \mathrm{mg} / \mathrm{kg}))$ were provided by a mineral block for sheep (Timac Potasco, Belgium).

Red clover, white clover and BDSs were provided in bales of approximately $270 \mathrm{~kg}$. These silages were from natural grassland pastures situated at the farm of origin (Berendrecht, Belgium, $51^{\circ} 20 \mathrm{~N} / 04^{\circ} 28 \mathrm{E}, 14 \mathrm{~m}$ a.s.l.) and without any type of fertilisation. These silages were baled during the summer of 2004 (at the second and third cuts). The silages were wilted for $48 \mathrm{~h}$ and no inoculum was used. Silage bales of intensive English ryegrass were made from a pasture with circa $70 \%$ of Lolium perenne - English ryegrass (the other $30 \%$ were mainly Bromus hordeaceus soft brome - and Lolium multiflorum - Italian ryegrass) and fertilised with organic manure (30 to 40 ton/ha cow manure) at the end of February 2005, with $200 \mathrm{~kg} / \mathrm{ha}$ of ammonium nitrate $(25 \% \mathrm{~N})$ on 21 March 2005 and with organic manure ( 25 ton/ha pig manure) after the first cut at the end of April 2005. Maize silage was produced from a maize crop fertilised with 30 to 40 ton/ha of cow or pig manure and $210 \mathrm{~kg} / \mathrm{ha} 30 \% \mathrm{~N}-10 \% \mathrm{P}_{2} \mathrm{O}_{5}$. Both the English ryegrass pasture and the maize crop were situated at the experimental farm of Ghent University at Melle, Belgium ( $50^{\circ} 59^{\prime} \mathrm{N} / 03^{\circ} 49^{\prime} \mathrm{E}, 11 \mathrm{~m}$ a.s.l.).

In addition to the silages, all groups received organic ground wheat and barley grains. The ratio of wheat and barley was adapted during the experimental period to meet energy and protein requirements for growth. Animals in group MSL received extra crushed linseed in order to provide $C 18: 3 n-3$ in the range of the supply of the forage silages. The MSL group received also $15 \mathrm{~g}$ of sodium bicarbonate daily, in order to prevent rumen acidosis. Animals had free access to water.

\section{Measurements and sampling}

The silage portions were prepared per pen every time a bale was opened (on average every 9 days for the groups BDS, WCS and RCS, and weekly for the IRS group). Maize silage portions were prepared weekly from the silo. All daily portions of silage for the different groups were kept in the fridge at $4^{\circ} \mathrm{C}$ until fed to the animals. Wheat, barley and crushed linseed portions were prepared every 3 days. Leftovers of silage were recovered daily and weighed to assess the average intake per pen. There were no leftovers of grains and linseed. The amount of silage and grains distributed and the barley/wheat ratio were adjusted according to the average weight and growth rate per pen in order to provide $110 \%$ of the energy (VEVI, Van Es, 1978; CVB, 2004) and protein (DVE, Tamminga et al., 1994; CVB, 2004) requirements.

All silages were sampled for FA analysis, DM determination and chemical composition at time of weighing. Wheat, barley and linseed were sampled every 4 weeks for FA analysis and chemical composition. Samples were taken directly to the lab where FA extraction and DM determination were performed immediately. Samples for chemical composition analysis were stored at $-20^{\circ} \mathrm{C}$.

At the end of the experimental period, the lambs were transported to a private abattoir (Ronse, Belgium) without prior fasting and slaughtered according to conventional practise. Ruminal (1 I) contents were sampled into plastic 
pots after thorough mixing, and kept refrigerated until arrival in the laboratory. To ensure correct sampling, the $\mathrm{pH}$ of rumen contents was measured at three different locations. Rumen subsamples $(25 \mathrm{ml})$ were prepared for volatile fatty acid (VFA) analysis, as soon as they arrived in the laboratory. Samples were acidified with $0.5 \mathrm{ml}$ of phosphoric/formic acid (10/1, vol/vol) and centrifuged for $15 \mathrm{~min}$ at $31000 \times \mathbf{g}$. The supernatant was recovered and $1 \mathrm{ml}$ was transferred to vials and analysed by gas chromatography (Schimadzu GC-14A, Belgium) according to Van Nevel and Demeyer (1977). The rest of the rumen samples were freeze-dried and kept at $-20^{\circ} \mathrm{C}$ until analysis of FA.

Meat and SC fat samples were taken $24 \mathrm{~h}$ after slaughter from chilled carcasses $\left(4^{\circ} \mathrm{C}\right)$. Meat samples were taken from the $m$. longissimus thoracis from the left side of the carcass (between T7 and T8). Meat and SC fat samples were stored vacuum packed at $-20^{\circ} \mathrm{C}$ until FA analysis. Meat samples were trimmed of external fat so that only IM fat was extracted and analysed.

\section{Chemical composition analysis}

Silage samples for chemical composition determination were freeze-dried, ground through a 1.5-mm mesh (Brabander, Duisburg, Germany) and further pooled per 4 weeks. Wheat, barley and crushed linseed were finely $(0.5$ to $1 \mathrm{~mm}$ ) ground (Grindomix GM 200, Retsch, Germany) and further analysed. Chemical composition analysis consisted of determination of crude protein, according to the Kjeldahl method (European Community, 1993), ADF and NDF using the method of Van Soest et al. (1991), and crude fat with the Soxhlet method (International Organisation for Standardisation, 1973). Results are presented in Table 1.

\section{Fatty acid analysis}

Extraction. FAs of all silage samples were extracted in duplicate with chloroform/methanol (2/1, vol/vol) (C/M), as described by Lourenço et al. (2007). Briefly, $5 \mathrm{~g}$ of fresh material were cut into $1 \mathrm{~cm}$ strips and homogenised for 1 min (Ultra-Turrax T25, IKA-Labortechnik, Belgium). The endogenous water was determined $\left(105^{\circ} \mathrm{C}\right.$ for $\left.4 \mathrm{~h}\right)$ in order to adjust the ratio of chloroform/methanol/water to $8 / 4 / 3$
( $\mathrm{vol} / \mathrm{vol} / \mathrm{vol})$. In all samples, $40 \mathrm{ml}$ of C/M (2/1, vol/vol) was added, and $10 \mathrm{mg}$ of nonadecanoic acid (C19:0; Sigma, Belgium) used as internal standard and samples were extracted overnight. The next morning, samples were centrifuged at $1821 \times \mathbf{g}$ for $10 \mathrm{~min}$ and the $\mathrm{C} / \mathrm{M}$ layer was recovered. In the second and third extraction step, 30 and $20 \mathrm{ml}$ of $\mathrm{C} / \mathrm{M}(2 / 1, \mathrm{vol} / \mathrm{vol})$ respectively, were added and the samples were centrifuged at $1821 \times \mathbf{g}$ for $10 \mathrm{~min}$ for every extraction step. The extracts were combined and washed once with distilled water and the C/M layer recovered. Finally, the extracts were brought to a final volume of $100 \mathrm{ml}$ with $\mathrm{C} / \mathrm{M}(2 / 1, \mathrm{vol} / \mathrm{vol})$.

Wheat, barley and linseed (finely ground, 0.5 to $1 \mathrm{~mm}$ (Grindomix GM 200) and rumen (freeze-dried and finely ground as for wheat, barley and linseed) samples were analysed in duplicate for FA as described by Lourenço et al. (2005b). Briefly, $2.5 \mathrm{~g}$ of sample was extracted overnight with $30 \mathrm{ml}$ of C/M (2/1, vol/vol), $20 \mathrm{ml}$ of distilled water and $10 \mathrm{mg}$ of nonadecanoic acid (C19:0) as internal standard. The samples were then centrifuged at $1821 \times \mathbf{g}$ for $10 \mathrm{~min}$ and the $\mathrm{C} / \mathrm{M}$ layer recovered. This procedure was repeated twice, adding $25 \mathrm{ml}$ of $\mathrm{C} / \mathrm{M}(2 / 1$, vol/ $/ \mathrm{vol})$ in the second and $20 \mathrm{ml}$ in the third extraction step. Finally, samples were washed with distilled water and the C/M layer was recovered. Extracts were brought to a final volume of $100 \mathrm{ml}$ with C/M (2/1, vol/vol).

Meat samples were extracted in duplicate as described by Raes et al. (2001). Briefly, $5 \mathrm{~g}$ of meat was homogenised for 30 s (Ultra-Turrax T25, IKA-Labortechnik, Belgium) and extracted overnight with $30 \mathrm{ml}$ of $\mathrm{C} / \mathrm{M}(2 / 1, \mathrm{vol} / \mathrm{vol})$ and $3 \mathrm{ml}$ of butylated hydroxytoluene (BHT) in chloroform $(0.1 \%$ w/vol). Samples were then filtered (Fiorini, S.A.) and the filtrate collected. The filter was washed twice with $10 \mathrm{ml}$ of $\mathrm{C} / \mathrm{M}(2 / 1, \mathrm{vol} / \mathrm{vol})$. The filtrate was then transferred to the extraction tubes and $15 \mathrm{ml}$ of distilled water was added. Samples were centrifuged at $1821 \times \mathbf{g}$ for $10 \mathrm{~min}$ and the $\mathrm{C} / \mathrm{M}$ layer recovered and evaporated with a rotavapor (Laborota $4000 \mathrm{WB}$, Germany) at $40^{\circ} \mathrm{C}$. The dry residue was then re-suspended in $10 \mathrm{ml}$ of $\mathrm{C} / \mathrm{M}(2 / 1, \mathrm{vol} / \mathrm{vol})$.

SC fat samples $(1 \mathrm{~g})$ were extracted using a procedure similar to that described above for FA extraction of meat

Table 1 Chemical composition of the five different silages $(n=3)$ and of the grains $(n=2)$ given to the animals ${ }^{t}$

\begin{tabular}{|c|c|c|c|c|c|}
\hline & $\mathrm{DM}(\mathrm{g} / \mathrm{kg})$ & NDF (g/kg DM) & ADF $(g / k g ~ D M)$ & Fat ( $\mathrm{g} / \mathrm{kg} \mathrm{DM})$ & Protein ( $/ \mathrm{kg} \mathrm{DM})$ \\
\hline \multicolumn{6}{|l|}{ Silages } \\
\hline Botanically diverse & 668 & 579 & 383 & 26.4 & 94.4 \\
\hline White clover & 609 & 530 & 348 & 32.5 & 113 \\
\hline Red clover & 521 & 523 & 366 & 30.3 & 106 \\
\hline Intensive ryegrass & 380 & 393 & 259 & 40.2 & 129 \\
\hline Maize & 351 & 471 & 250 & 40.5 & 71.6 \\
\hline \multicolumn{6}{|l|}{ Grains } \\
\hline Wheat & - & 314 & 58.5 & 46.0 & 111 \\
\hline Barley & - & 263 & 70.6 & 30.8 & 86.0 \\
\hline Linseed & - & 336 & 175 & 394 & 186 \\
\hline
\end{tabular}

${ }^{+}$Abbreviations are: $\mathrm{DM}=$ dry matter; $\mathrm{NDF}=$ neutral-detergent fibre; $\mathrm{ADF}=$ acid-detergent fibre. 
(Raes et al., 2001); however, the bottom layer was recovered into volumetric flasks after washing with distilled water and was brought to a final volume of $100 \mathrm{ml}$ with Cl M (2/1, vol/vol).

Methylation. For methylation of IM and SC lipids, $2 \mathrm{ml}$ of extract was taken and $1 \mathrm{ml}$ of nonadecanoic acid $(2 \mathrm{mg} / \mathrm{ml}$; C19:0; Sigma) was added. For methylation of silage, wheat, barley, linseed and rumen lipids, $10 \mathrm{ml}$ of extract was used. Samples were methylated at $50^{\circ} \mathrm{C}$ with $\mathrm{NaOH}$ in methanol $(0.5 \mathrm{~mol} / \mathrm{l})$ followed by $\mathrm{HCl} / \mathrm{methanol}(1 / 1$, vol/vol) according to Raes et al. (2001).

Gas chromatography (GC). Fatty acid methylesters (FAME) were analysed on a Hewlett-Packard 6890 gas chromatograph (Hewlett-Packard Co., Belgium) with a CP-Sil88 column for FAME $(100 \mathrm{~m} \times 0.25 \mathrm{~mm} \times 0.2 \mu \mathrm{m}$; Chrompack Inc., The Netherlands). For more detailed information about the GC conditions for analysis of silage, wheat, barley, linseed, rumen, IM and SC fat samples, we refer to Raes et al. (2004b). Separation of the FA C16:1 t9 and iso C17:0 was not possible due to the status of the GC column. Conjugated linoleic acid cis-cis (CLAcc) isomers and CLA trans-trans (CLAtt) isomers are reported as the sum of all CLA isomers with two cis or trans double bounds, respectively, as with the GC method used it was not possible to separate all CLAcc and all CLAtt isomers.

\section{Statistics}

A one-way ANova was used to compare the feed FA content and composition of each group and to evaluate the effect of the different diets on rumen, IM and SC fat FA and rumen VFA, according to $Y_{i}=\mu+B_{i}+\varepsilon_{i}$, where $\mu$ is the overall mean, $B_{i}$ the effect of the different silages and $\varepsilon_{i}$ the residual error. Five orthogonal contrasts were applied: (1) MSL diet $v$. the four other diets to compare the supply of forage C18:3 n-3 (mainly unesterified) v. linseed C18:3 n-3 (mainly in triacylglycerols); (2) BDS diet $v$. WCS + RCS diets to compare botanical diversity with clover-rich diets; (3) BDS diet $v$. IRS diet; (4) WCS + RCS diets $v$. IRS diet to compare clover-rich diets with ryegrass; (5) WCS diet $v$. RCS diet.

Principal component analysis (PCA), based on the correlation matrix, was conducted to determine components which account for most of the total variation in odd- and branched-chain FA (OBCFA). Each object (animal $X$ treatment, $n=30$ ) was considered to be a data vector of 11 variables (iso C13:0, anteiso C13:0, C13:0, iso $\mathrm{C} 14: 0$, iso $\mathrm{C} 15: 0$, anteiso $\mathrm{C} 15: 0, \mathrm{C15}: 0$, iso $\mathrm{C} 16: 0$, anteiso $\mathrm{C} 17: 0, \mathrm{C} 17: 0$ and $\mathrm{C} 17: 1 \mathrm{c} 9$ all expressed as $\mathrm{g} / 100 \mathrm{~g}$ of FAME). The principal component scores are presented in a scatter plot to evaluate grouping of treatments. Statistical analyses were performed using Statistical Packages for the Social Sciences (2003).

\section{Results}

Live-weight gain of the animals in group BDS tended to be lower compared with the animals of the other groups, with an average live weight at slaughter of $33.0 \mathrm{~kg}$ for the BDS group compared with 37.7, 35.1, 40.8 and 37.9 for the WCS, RCS, IRS and MSL groups, respectively.

\section{Diets}

In Table 2, total average individual FA and proportions of FA ingested by the animals is presented. For the first four diets, $96 \%$ of all FA is reported, whereas for diet MSL, $98 \%$ of all FA is reported. Animals of the MSL group ingested the highest total amount of FA, followed by animals of group IRS, with animals fed the BDS diet ingesting the lowest amount. Proportions of C16:0 in the MSL diet were significantly lower than for the four forage diets. Proportions of C18:2 n- 6 were significantly higher for the group MSL, followed by BDS, WCS and RCS groups and were lowest for the IRS diet. On the other hand, proportions of $\mathrm{C} 18: 3 \mathrm{n}-3$ were lowest for the MSL group and highest for the IRS diet. Nevertheless, in terms of C18:3 n-3 intake, the MSL group was intermediate $(9.67 \mathrm{~g} /$ day) between the IRS (15.1 g/day) and the clover diets $(7.04$ and $6.45 \mathrm{~g} /$ day, respectively), whereas the BDS group ingested the lowest C18:3 n-3 amount ( $4.48 \mathrm{~g} /$ day).

Proportions of PUFA (C18:2 n- $6+\mathrm{C} 18: 3 n-3)$ were similar for diets BDS, WCS, RCS and MSL $(61.3,62.3,62.3$ and $63.7 \mathrm{~g} /$ $100 \mathrm{~g}$ of FAME for BDS, WCS, RCS and MSL respectively) while this was higher for diet IRS (74.5 g/100 $\mathrm{g}$ of FAME).

\section{Fatty acid composition of rumen contents}

Total rumen concentrations of VFA, proportions of individual VFA and VFA ratios are presented in Table 3. Animals in the MSL group presented a significantly lower proportion of acetate and a significantly higher proportion of propionate compared with the forage silage fed groups. Proportions of butyrate did not differ significantly between the five groups, with only a trend $(P=0.060)$ for animals in BDS group to show higher butyrate proportions than animals in the IRS group. Lambs in the IRS group tended to have higher valerate proportions compared with lambs in the BDS group $(P=0.084)$ and in the WCS + RCS groups $(P=0.083)$.

Total FA concentration and proportions of FA of rumen contents are presented in Table 4. For rumen contents, the proportions of C18-FA are also expressed relative to the sum of all C18-FA identified, as this allows a better evaluation of rumen hydrogenation when dietary supply of C18-FA differs (Chow et al., 2004). Rumen contents of MSL animals clearly had the highest amount of total FA, followed by animals in the IRS group, WCS and RCS group, whereas total rumen FA content was lowest for animals of the BDS group. Proportions of C18:2 n-6 were significantly lower in rumen contents of IRS animals compared with the BDS group and only a trend was found for lower proportions of C18:2 n-6 for the IRS group compared with the WCS + RCS groups $(P=0.088)$. C18:3 n-3 proportions were higher in the rumen contents of the MSL group than in forage silage fed groups and were lower in animals of the BDS group than in animals of WCS + RCS groups. Further, lambs fed WCS tended $(P=0.077)$ to have lower proportions of $C 18: 3 n-3$ in their rumen contents than lambs fed RCS. 
Table 2 Total average individual DM ( $\mathrm{kg} /$ day) and FA ( $\mathrm{g} /$ day) intakes and proportions of FA ( $/ \mathrm{g} / 100 \mathrm{~g} F A M E)$ ingested by the animals fed the five different diets $(\mathrm{n}=11)$

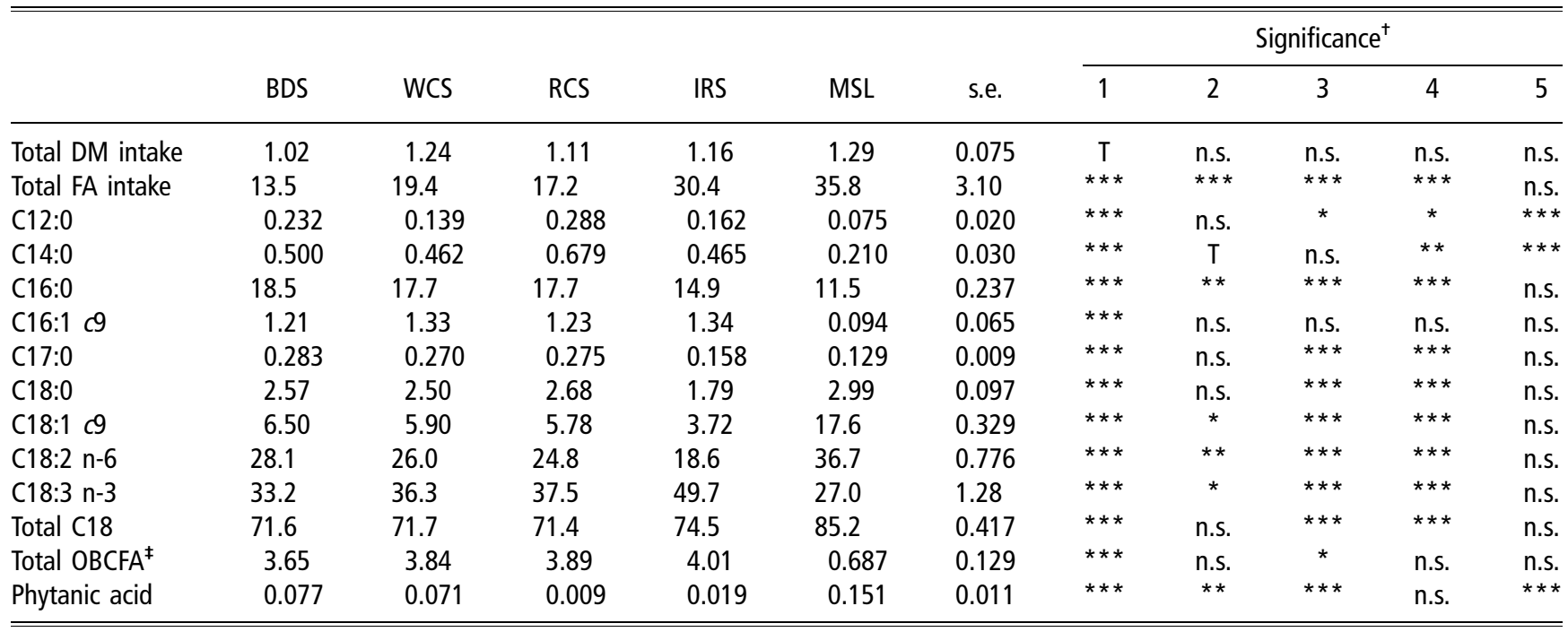

Abbreviations are: DM = dry matter; FA: fatty acid; FAME: FA methylesters; BDS = botanically diverse silage; WCS = white clover silage; RCS = red clover silage; IRS = intensive English ryegrass silage; $M S L=$ crushed linseed and maize silage; s.e.: standard error; OBFCA: odd- and branched-chain fatty acid.

${ }^{\dagger} \mathrm{T}=$ trend $(0.1<P<0.05) ;{ }^{*}=0.05<P<0.01 ;{ }^{* *}=0.01<P<0.001 ;{ }^{* * *}=P<0.001 ;$ n.s. = non-significant; 1 = orthogonal contrast MSL $v$. forages; $2=$ orthogonal contrast BDS $v$. clover diets; $3=$ orthogonal contrast BDS v. IRS; $4=$ orthogonal contrast clover diets $v$. IRS; $5=$ orthogonal contrast WCS $v$. RCS. ${ }^{\ddagger}$ Total OBCFA - sum of all odd- and branched-chain fatty acids: C13:0 iso; C13;0 anteiso; C13:0; C14:0 iso; C15:0 iso; C15:0 anteiso; C15:0; C16:0 iso; C17:0 iso; C17:0 anteiso; C17:0; C17:1 c9.

Table 3 Total VFA concentration (mmol/l) and relative proportions of VFA (mmol/mol total VFA) in the rumen of animals fed the five different diets $(\mathrm{n}=6)$

\begin{tabular}{|c|c|c|c|c|c|c|c|c|c|c|c|}
\hline & \multirow[b]{2}{*}{ BDS } & \multirow[b]{2}{*}{ WCS } & \multirow[b]{2}{*}{ RCS } & \multirow[b]{2}{*}{ IRS } & \multirow[b]{2}{*}{ MSL } & \multirow[b]{2}{*}{ s.e. } & \multicolumn{5}{|c|}{ Significance $^{+}$} \\
\hline & & & & & & & 1 & 2 & 3 & 4 & 5 \\
\hline Total & 128 & 136 & 147 & 120 & 112 & 9.00 & * & n.s. & n.s. & $\mathrm{T}$ & n.s. \\
\hline \multicolumn{12}{|l|}{ Relative proportions of VFA } \\
\hline Acetate & 698 & 720 & 722 & 685 & 592 & 22.1 & $* * *$ & n.s. & n.s. & n.s. & n.s. \\
\hline Propionate & 137 & 134 & 137 & 168 & 223 & 18.7 & $* *$ & n.s. & n.s. & n.s. & n.s. \\
\hline Isobutyrate & 8.62 & 7.62 & 7.42 & 8.62 & 31.0 & 2.99 & $* * *$ & n.s. & n.s. & n.s. & n.s. \\
\hline Butyrate & 140 & 125 & 115 & 111 & 124 & 10.5 & n.s. & n.s. & $\mathrm{T}$ & n.s. & n.s. \\
\hline Isovalerate & 7.84 & 5.52 & 7.04 & 6.84 & 14.7 & 1.55 & $* * *$ & n.s. & n.s. & n.s. & n.s. \\
\hline Valerate & 9.16 & 8.92 & 12.4 & 20.5 & 15.6 & 4.46 & n.s. & n.s. & $\mathrm{T}$ & $\mathrm{T}$ & n.s. \\
\hline Rumen pH & 5.67 & 5.49 & 5.56 & 5.42 & 5.84 & 0.112 & * & n.s. & n.s. & n.s. & n.s. \\
\hline
\end{tabular}

Abbreviations are: VFA = volatile fatty acid; BDS = botanically diverse silage; $W C S=$ white clover silage; RCS = red clover silage; IRS = intensive English ryegrass silage; $\mathrm{MSL}=$ crushed linseed and maize silage; s.e.: standard error.

${ }^{\mathrm{T}} \mathrm{T}=$ trend $(0.1<P<0.05) ;{ }^{*}=0.05<P<0.01 ;{ }^{* *}=0.01<P<0.001 ;{ }^{* * *}=P<0.001 ;$ n.s. $=$ non-significant; $1=$ orthogonal contrast MSL $v$. forages; $2=$ orthogonal contrast BDS v. clover diets; $3=$ orthogonal contrast BDS v. IRS; $4=$ orthogonal contrast clover diets $v$. IRS; $5=$ orthogonal contrast WCS v. RCS.

Rumen contents of BDS animals presented a higher sum of the proportions of biohydrogenation intermediates (C18:1 t11, C18:1 t15, C18:1 c15, C18:2 t11 c15, CLA c9t11 and $\mathrm{C} 18: 3 \mathrm{C} 9 \mathrm{t1} 1 \mathrm{C15})$ of the major rumen biohydrogenation pathways of $C 18: 2 n-6$ and $C 18: 3 n-3$ than the other groups ( $4.53 \mathrm{~g} / 100 \mathrm{~g}$ of FAME v. 3.88, 4.30, 3.60 and $3.44 \mathrm{~g} / 100 \mathrm{~g}$ of FAME for BDS $v$. WCS, RCS, IRS and MSL groups, respectively). This is mainly due to the isomers C18:1 t1 1 and CLA c9t11. In addition, rumen contents of animals of the WCS and RCS groups contained higher proportions of C18:2 $111 \mathrm{c15}$ compared with BDS and IRS groups and RCS animals had higher C18:1 $\mathrm{C15}$ and C18:1 t15 proportions than WCS animals. Rumen contents of animals of groups IRS and MSL had significantly higher proportions of C18:0 and lower accumulation of the major biohydrogenation intermediates compared with the other groups, except C18:1 C15 and C18:1 t15 proportions which were highest for the IRS group. The differences seen between groups remain when these intermediates are expressed relative to the sum of all C18-FA (Table 4). On the other hand, concerning intermediates of secondary biohydrogenation pathways, rumen contents of group MSL contained the 
Lourenço, De Smet, Raes and Fievez

Table 4 Total concentration (mg/g dry matter) and proportions of individual FAs ( $\mathrm{g} / 100 \mathrm{~g}$ FAME) in rumen contents of animals fed the five different diets $(\mathrm{n}=6)$

\begin{tabular}{|c|c|c|c|c|c|c|c|c|c|c|c|}
\hline \multirow[b]{2}{*}{ FAs } & \multirow[b]{2}{*}{ BDS } & \multirow[b]{2}{*}{ WCS } & \multirow[b]{2}{*}{ RCS } & \multirow[b]{2}{*}{ IRS } & \multirow[b]{2}{*}{ MSL } & \multirow[b]{2}{*}{ s.e. } & \multicolumn{5}{|c|}{ Significance $^{\dagger}$} \\
\hline & & & & & & & 1 & 2 & 3 & 4 & 5 \\
\hline Total & 24.6 & 33.6 & 33.5 & 50.2 & 75.1 & 3.54 & $* * *$ & * & $* * *$ & $* *$ & n.s. \\
\hline C12:0 & 0.186 & 0.175 & 0.166 & 0.117 & 0.122 & 0.028 & n.s. & n.s. & T & n.s. & n.s. \\
\hline C14:0 & 0.834 & 0.703 & 0.635 & 0.492 & 0.188 & 0.052 & $* * *$ & * & $* * *$ & * & n.s. \\
\hline C16:0 & 22.5 & 19.0 & 18.8 & 14.3 & 11.6 & 0.511 & $* * *$ & $* * *$ & $* * *$ & $* * *$ & n.s. \\
\hline C18:0 & 40.3 & 48.4 & 44.1 & 53.8 & 59.0 & 2.17 & $* * *$ & * & $\star * *$ & * & n.s. \\
\hline C18:1 t9 & 0.098 & 0.115 & 0.156 & 0.163 & 0.139 & 0.017 & n.s. & $T$ & * & n.s. & n.s. \\
\hline C18:1t10 & 0.271 & 0.315 & 0.443 & 0.489 & 0.926 & 0.122 & $* * *$ & n.s. & n.s. & n.s. & n.s. \\
\hline C18:1t11 & 2.51 & 2.01 & 2.20 & 1.05 & 1.63 & 0.278 & n.s. & n.s. & $* *$ & $* *$ & n.s. \\
\hline C18:1t15 & 0.309 & 0.573 & 0.978 & 1.77 & 0.904 & 0.104 & n.s. & $* *$ & $* * *$ & $* * *$ & * \\
\hline C18:1c9 & 5.70 & 4.05 & 4.64 & 5.03 & 5.81 & 0.467 & $T$ & * & n.s. & n.s. & n.s. \\
\hline C18:1C15 & 0.070 & 0.040 & 0.073 & 0.109 & 0.068 & 0.013 & n.s. & n.s. & $\mathrm{T}$ & $* *$ & $\mathrm{~T}$ \\
\hline C18:2 t11C15 & 0.185 & 0.294 & 0.316 & 0.179 & 0.227 & 0.037 & n.s. & $*$ & n.s. & * & n.s. \\
\hline C18:2 n-6 & 5.91 & 4.29 & 4.97 & 2.92 & 5.46 & 0.753 & n.s. & n.s. & * & $\mathrm{T}$ & n.s. \\
\hline CLAC9t11 & 1.31 & 0.788 & 0.589 & 0.330 & 0.517 & 0.123 & $\mathrm{~T}$ & $* * *$ & $* * *$ & * & n.s. \\
\hline $\mathrm{CLAC} 11+13$ & 0.159 & 0.105 & 0.123 & 0.045 & 0.052 & 0.043 & n.s. & n.s. & $\mathrm{T}$ & n.s. & n.s. \\
\hline CLAt $10 C 12$ & 0.137 & 0.077 & 0.074 & 0.053 & 0.027 & 0.018 & $* *$ & $*$ & $* *$ & n.s. & n.s. \\
\hline CLACC & 0.056 & 0.088 & 0.067 & 0.070 & 0.023 & 0.024 & $\mathrm{~T}$ & n.s. & n.s. & n.s. & n.s. \\
\hline CLAtt & 0.097 & 0.070 & 0.113 & 0.381 & 0.148 & 0.032 & n.s. & n.s. & $* * *$ & $* * *$ & n.s. \\
\hline C18:3c9t11c15 & 0.141 & 0.171 & 0.148 & 0.158 & 0.091 & 0.077 & n.s. & n.s. & n.s. & n.s. & n.s. \\
\hline C18:3 n-3 & 1.00 & 1.62 & 2.61 & 1.76 & 4.87 & 0.386 & $* * *$ & * & n.s. & n.s. & $\mathrm{T}$ \\
\hline Total C18 & 59.7 & 64.3 & 63.7 & 71.2 & 82.4 & 0.981 & $* * *$ & $* *$ & $* * *$ & $* * *$ & n.s. \\
\hline Total MUFA ${ }^{\ddagger}$ & 13.2 & 11.9 & 14.3 & 15.1 & 12.6 & 1.12 & n.s. & n.s. & n.s. & n.s. & n.s. \\
\hline Total OBCFA & 8.00 & 6.27 & 6.65 & 4.99 & 2.94 & 0.371 & $* * *$ & $* *$ & $* * *$ & $* *$ & n.s. \\
\hline $\mathrm{C} 16: 1$ t9+ iso C17:0 & 1.24 & 0.726 & 0.629 & 0.430 & 0.424 & 0.061 & $* * *$ & $* * *$ & $\star * *$ & $* *$ & n.s. \\
\hline iso $\mathrm{C} 14: 0$ & 0.170 & 0.177 & 0.253 & 0.239 & 0.019 & 0.029 & $* * *$ & $\mathrm{~T}$ & n.s. & $T$ & n.s. \\
\hline \multicolumn{12}{|c|}{ C18 FAs as $\%$ of total C18 } \\
\hline C18:0 & 67.5 & 75.2 & 69.1 & 75.5 & 71.5 & 2.54 & n.s. & n.s. & * & n.s. & $\mathrm{T}$ \\
\hline C18:1 t9 & 0.164 & 0.179 & 0.246 & 0.230 & 0.170 & 0.122 & n.s. & n.s. & $\mathrm{T}$ & n.s. & $\mathrm{T}$ \\
\hline C18:1 t10 & 0.449 & 0.490 & 0.697 & 0.688 & 1.13 & 0.151 & $* *$ & n.s. & n.s. & n.s. & n.s. \\
\hline C18:1 t11 & 4.23 & 3.12 & 3.46 & 1.48 & 1.99 & 0.396 & * & $\mathrm{T}$ & $* * *$ & $* *$ & n.s. \\
\hline C18:1 t15 & 0.514 & 0.894 & 1.54 & 2.49 & 1.10 & 0.150 & n.s. & $* *$ & $* * *$ & $* * *$ & ** \\
\hline C18:1 c9 & 9.62 & 6.31 & 7.30 & 7.07 & 7.08 & 0.689 & n.s. & $* *$ & * & n.s. & n.s. \\
\hline C18:1 c15 & 0.118 & 0.063 & 0.116 & 0.153 & 0.082 & 0.018 & n.s. & n.s. & n.s. & * & $*$ \\
\hline C18:2 t11C15 & 0.320 & 0.457 & 0.499 & 0.252 & 0.274 & 0.058 & n.s. & * & n.s. & $* *$ & n.s. \\
\hline C18:2 n-6 & 9.74 & 6.68 & 7.78 & 4.10 & 6.66 & 1.06 & n.s. & $\mathrm{T}$ & $* *$ & * & n.s. \\
\hline CLA $c 9 t 11$ & 2.22 & 1.23 & 0.930 & 0.465 & 0.628 & 0.204 & * & $* * *$ & $* * *$ & * & n.s. \\
\hline CLA $C 11 t 13$ & 0.282 & 0.164 & 0.194 & 0.063 & 0.063 & 0.073 & n.s. & n.s. & $T$ & n.s. & n.s. \\
\hline CLA $t 10 c 12$ & 0.236 & 0.121 & 0.116 & 0.074 & 0.033 & 0.033 & $* *$ & $* *$ & $* *$ & n.s. & n.s. \\
\hline CLA cC & 0.095 & 0.137 & 0.106 & 0.099 & 0.029 & 0.039 & $\mathrm{~T}$ & n.s. & n.s. & n.s. & n.s. \\
\hline CLA tt & 0.166 & 0.108 & 0.179 & 0.536 & 0.178 & 0.044 & n.s. & n.s. & $* * *$ & $* * *$ & n.s. \\
\hline C18:3 c9t11c15 & 0.231 & 0.261 & 0.228 & 0.219 & 0.109 & 0.112 & n.s. & n.s. & n.s. & n.s. & n.s. \\
\hline C18:3 n-3 & 1.69 & 2.52 & 4.11 & 2.46 & 5.91 & 0.479 & $* * *$ & $* *$ & n.s. & n.s. & * \\
\hline
\end{tabular}

Abbreviations are: FA: fatty acid; FAME: FA methylesters; BDS = botanically diverse silage; WCS = white clover silage; RCS = red clover silage; IRS = intensive English ryegrass silage; MSL = crushed linseed and maize silage; s.e.: standard error; MUFA = monounsaturated fatty acid; OBFCA: odd- and branched-chain fatty acid.

${ }^{\dagger} \mathrm{T}=$ trend $(0.1<P<0.05) ;{ }^{*}=0.05<P<0.01 ;{ }^{* *}=0.01<P<0.001 ;{ }^{* *}=P<0.001 ;$ n.s. = non-significant; $1=$ orthogonal contrast linseed $v$. forages; $2=$ orthogonal contrast BDS $v$. clover diets; $3=$ orthogonal contrast BDS $v$. IRS; $4=$ orthogonal contrast clover diets $v$. IRS; $5=$ orthogonal contrast WCS $v$. RCS. ${ }^{\ddagger}$ Total MUFA = sum of monounsaturated fatty acids: C14:1 c9, C15:1 c9, C16:1 t9, C16:1 c9, C17:1 c9, C18:1 t6-t8, C18:1 t9, C18:1 t10, C18:1 t11, C18:1 t12t14, C18:1 t15, C18:1 c9, C18:1 c10, C18:1 c11, C18:1 c12, C18:1 c14, C18:1 c15 and C20:1 c9. Total OBCFA= sum of all odd- and branched-chain fatty acids: C13:0 iso; C13:0 anteiso; C13:0; C14:0 iso; C15:0 iso; C15:0 anteiso; C15:0; C16:0 iso; C17:0 iso; C17:0 anteiso; C17:0; C17:1 c9.

highest proportions of $C 18: 1$ t10 compared with the forage silage fed groups, whereas BDS animals had unexpectedly significantly higher CLA $t 10 \mathrm{C} 12$ proportions in their rumen contents compared with the other groups.
Subcutaneous and intramuscular fatty acid composition The FA acid pattern of the SC fat was a partial reflection of what was found in the rumen (Table 5). Total concentration of FA in the SC fat was similar between groups as well as 
Silage composition affects lamb fatty acid metabolism

Table 5 Total concentration (mg/g fat) and proportions of individual FAs (g/100 g FAME) in subcutaneous fat of animals fed the five different diets $(\mathrm{n}=6)$

\begin{tabular}{|c|c|c|c|c|c|c|c|c|c|c|c|}
\hline \multirow[b]{2}{*}{ FAs } & \multirow[b]{2}{*}{ BDS } & \multirow[b]{2}{*}{ WCS } & \multirow[b]{2}{*}{ RCS } & \multirow[b]{2}{*}{ IRS } & \multirow[b]{2}{*}{ MSL } & \multirow[b]{2}{*}{ s.e. } & \multicolumn{5}{|c|}{ Significance $^{\dagger}$} \\
\hline & & & & & & & 1 & 2 & 3 & 4 & 5 \\
\hline Total & 844 & 806 & 858 & 875 & 852 & 48.6 & n.s. & n.s. & n.s. & n.s. & n.s. \\
\hline $\mathrm{C} 12: 0$ & 0.772 & 0.443 & 0.413 & 0.197 & 0.361 & 0.102 & n.s. & * & $* * *$ & $\mathrm{~T}$ & n.s. \\
\hline C14:0 & 6.38 & 4.73 & 4.48 & 3.77 & 4.00 & 0.504 & n.s. & $* *$ & * & n.s. & n.s. \\
\hline C16:0 & 24.4 & 26.8 & 23.6 & 26.3 & 22.5 & 1.11 & * & n.s. & n.s. & n.s. & $\mathrm{T}$ \\
\hline C18:0 & 20.8 & 21.1 & 21.9 & 22.2 & 21.9 & 1.74 & n.s. & n.s. & n.s. & n.s. & n.s. \\
\hline C18:1 t9 & 0.198 & 0.176 & 0.238 & 0.169 & 0.295 & 0.029 & $* *$ & n.s. & n.s. & n.s. & n.s. \\
\hline C18:1t10 & 0.421 & 0.335 & 0.368 & 0.281 & 0.828 & 0.137 & $* *$ & n.s. & n.s. & n.s. & n.s. \\
\hline C18:1t11 & 1.29 & 0.816 & 0.916 & 0.630 & 1.09 & 0.175 & n.s. & $\mathrm{T}$ & * & n.s. & n.s. \\
\hline C18:1t15 & 0.369 & 0.422 & 0.464 & 0.645 & 0.398 & 0.039 & $\mathrm{~T}$ & n.s. & $* * *$ & $* * *$ & n.s. \\
\hline C18:1c9 & 28.3 & 28.4 & 26.7 & 29.0 & 30.8 & 0.984 & * & n.s. & n.s. & n.s. & n.s. \\
\hline C18:1c15 & 0.068 & 0.070 & 0.081 & 0.082 & 0.062 & 0.010 & n.s. & n.s. & n.s. & n.s. & n.s. \\
\hline C18:2 t11c15 & 0.214 & 0.127 & 0.170 & 0.165 & 0.150 & 0.030 & n.s. & $T$ & n.s. & n.s. & n.s. \\
\hline C18:2 n-6 & 1.39 & 1.32 & 1.63 & 0.955 & 2.33 & 0.145 & $* * *$ & n.s. & * & ** & n.s. \\
\hline CLAc9t11 & 0.665 & 0.396 & 0.412 & 0.225 & 0.568 & 0.098 & n.s. & * & $* *$ & n.s. & n.s. \\
\hline CLAt10c12 & 0.043 & 0.033 & 0.042 & 0.005 & 0.010 & 0.008 & * & n.s. & $* *$ & $* *$ & n.s. \\
\hline CLACC & 0.042 & 0.034 & 0.041 & 0.060 & 0.024 & 0.007 & * & n.s. & $\mathrm{T}$ & * & n.s. \\
\hline CLAtt & 0.037 & 0.033 & 0.031 & 0.041 & 0.030 & 0.005 & n.s. & n.s. & n.s. & n.s. & n.s. \\
\hline C18:3c9t11c15 & 0.032 & 0.019 & 0.016 & 0.012 & 0.011 & 0.006 & n.s. & $\mathrm{T}$ & * & n.s. & n.s. \\
\hline C18:3 n-3 & 1.04 & 1.14 & 1.42 & 1.22 & 1.24 & 0.125 & n.s. & n.s. & n.s. & n.s. & n.s. \\
\hline Total OBCFA ${ }^{\ddagger}$ & 6.22 & 6.40 & 6.83 & 5.24 & 5.30 & 0.271 & $* *$ & n.s. & * & $* * *$ & n.s. \\
\hline Total SFA & 55.6 & 56.5 & 54.1 & 55.2 & 51.4 & 1.53 & * & n.s. & n.s. & n.s. & n.s. \\
\hline Total MUFA & 35.3 & 34.0 & 32.7 & 35.5 & 38.8 & 1.16 & $* *$ & n.s. & n.s. & n.s. & n.s. \\
\hline Total PUFA & 3.93 & 3.57 & 4.22 & 3.34 & 4.93 & 0.323 & $* *$ & n.s. & n.s. & n.s. & n.s. \\
\hline n-6/n-3 ratio ${ }^{\ddagger}$ & 1.38 & 1.16 & 1.22 & 0.799 & 1.90 & 0.092 & $* * *$ & n.s. & $* * *$ & ** & n.s. \\
\hline $\mathrm{P} / \mathrm{S}$ ratio ${ }^{\ddagger}$ & 0.047 & 0.047 & 0.061 & 0.042 & 0.074 & 0.005 & $* * *$ & n.s. & n.s. & $\mathrm{T}$ & $\mathrm{T}$ \\
\hline
\end{tabular}

Abbreviations are: FA: fatty acid; FAME: FA methylesters; $B D S=$ botanically diverse silage; $W C S=$ white clover silage; $R C S=$ red clover silage; IRS $=$ intensive English ryegrass silage; MSL = crushed linseed and maize silage; s.e.: standard error; OBFCA: odd- and branched-chain fatty acid; SFA: saturated fatty acid; MUFA $=$ monounsaturated fatty acid; PUFA $=$ polyunsaturated fatty acid.

${ }^{\dagger} \mathrm{T}=$ trend $(0.1<P<0.05) ;{ }^{*}=0.05<P<0.01 ;{ }^{* *}=0.01<P<0.001 ;{ }^{* * *}=P<0.001 ;$ n.s. $=$ non-significant; 1 = orthogonal contrast linseed $v$. forages; $2=$ orthogonal contrast BDS v. clover diets; $3=$ orthogonal contrast BDS v. IRS; $4=$ orthogonal contrast clover diets $v$. IRS; $5=$ orthogonal contrast WCS v. RCS. ${ }^{*}$ Total OBCFA = sum of all odd- and branched-chain fatty acids: C13:0 iso; C13:0 anteiso; C13:0; C14:0 iso; C15:0 iso; C15:0 anteiso; C15:0; C16:0 iso; C17:0 iso; C17:0 anteiso; C17:0; C17:1 c9. Total SFA=sum of saturated fatty acids: C10:0, C12:0, C13:0; C14:0, C15:0, C16:0, C17:0, C18:0 and C20:0.

Total MUFA = sum of monounsaturated fatty acids: C14:1 c9, C15:1 c9, C16:1 t9, C16:1 c9, C17:1 c9, C18:1 t6-t8, C18:1 t9, C18:1 t10, C18:1 t11, C18:1

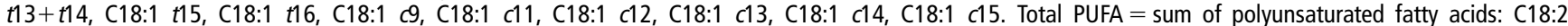
c9c12, C18:2 t9t12, C18:2 t11c15, C18:2 n-6, C18:3 n-3, CLA c9t11, CLA t10c12, CLA cc, CLA tt and C18:3 c9t11c15.

$n-6 / n-3$ ratio $=$ ratio between $C 18: 2 n-6$ and $C 18: 3 n-3$. P/S ratio $=$ ratio between the sum of $C 18: 2 n-6$ and $C 18: 3 n-3$, and the sum of $C 14: 0, C 16: 0$ and C18:0.

the $\mathrm{C} 18: 0$ and $\mathrm{C} 18: 3 \mathrm{n}-3$ proportions. Nevertheless, higher proportions of C18:2 n-6 were found in the SC fat of animals in group MSL and lower proportions in group IRS. The proportion of CLA c9t11 in the SC fat was significantly higher for animals of the BDS group compared with groups IRS and WCS + RCS. Concerning other CLA isomers, proportions of CLA $110 \mathrm{C} 12$ were highest for animals in groups BDS, WCS and RCS than for animals of IRS and MSL groups, whereas CLAcc proportions were higher in the SC fat for animals of the IRS group compared with the other groups and proportions of CLAtt were similar between groups.

Neither total concentration of FA nor the proportions of C18:3 n-3 in the IM fat differed between groups (Table 6). Similarly to what was found for the rumen contents, lower proportions of C18:2 n-6 and CLA C9t11 were found in the IM fat of IRS animals, and proportions of CLA $t 10 \mathrm{C} 12$ were significantly higher for BDS, WCS and RCS animals compared with the IRS and MSL groups. Proportions of CLAcc tended to be higher for animals of IRS group $(P=0.082)$ compared with BDS group and CLAtt proportions did not differ between groups. Proportions of C18:1 c9 tended to be higher in the IM fat of animals in the MSL group compared with the other groups $(P=0.096)$ as seen for the rumen contents. Finally, proportions of $C 20: 4 n-6$, $C 20: 5 n-3, C 22: 5 n-3$ and C22:6n-3 in the IM fat did not differ between groups. Nevertheless, in the muscle of BDS animals, higher C20:5 n-3/C18:3 n-3 and C22:5n-3/C18:3 $\mathrm{n}-3$ indices for desaturation and elongation activity, as calculated by ratios of product to precursor FA, were observed than in the muscle of MSL and IRS animals. In the muscle of animals fed clover diets (WCS and RCS), higher C20:5 n-3/C18:3n-3 and C22:5 n-3/C18:3n-3 indices for desaturation and elongation activity were also observed than in the muscle of IRS animals. 
Table 6 Total concentration ( $\mathrm{mg} / \mathrm{g}$ meat) and proportions of individual FAs (g/100 g FAME) in intramuscular fat of animals fed the five different diets $(\mathrm{n}=6)$

\begin{tabular}{|c|c|c|c|c|c|c|c|c|c|c|c|}
\hline \multirow[b]{2}{*}{ FAs } & \multirow[b]{2}{*}{ BDS } & \multirow[b]{2}{*}{ WCS } & \multirow[b]{2}{*}{ RCS } & \multirow[b]{2}{*}{ IRS } & \multirow[b]{2}{*}{ MSL } & \multirow[b]{2}{*}{ s.e. } & \multicolumn{5}{|c|}{ Significance $^{\dagger}$} \\
\hline & & & & & & & 1 & 2 & 3 & 4 & 5 \\
\hline Total & 17.9 & 17.6 & 18.5 & 23.8 & 25.4 & 3.19 & n.s. & n.s. & n.s. & n.s. & n.s. \\
\hline C12:0 & 0.422 & 0.403 & 0.349 & 0.226 & 0.273 & 0.053 & n.s. & n.s. & $*$ & * & n.s. \\
\hline C14:0 & 3.58 & 3.39 & 3.17 & 2.71 & 3.00 & 0.297 & n.s. & n.s. & * & n.s. & n.s. \\
\hline C16:0 & 21.1 & 22.6 & 21.9 & 23.6 & 22.6 & 0.961 & n.s. & n.s. & $\mathrm{T}$ & n.s. & n.s. \\
\hline C18:0 & 15.5 & 16.8 & 17.2 & 17.3 & 17.5 & 0.939 & n.s. & n.s. & n.s. & n.s. & n.s. \\
\hline C18:1 t9 & 0.136 & 0.144 & 0.192 & 0.165 & 0.253 & 0.030 & * & n.s. & n.s. & n.s. & n.s. \\
\hline C18:1t10 & 0.345 & 0.380 & 0.411 & 0.247 & 0.445 & 0.081 & n.s. & n.s. & n.s. & n.s. & n.s. \\
\hline C18:1t11 & 0.567 & 0.596 & 0.645 & 0.353 & 0.550 & 0.095 & n.s. & n.s. & n.s. & * & n.s. \\
\hline C18:1t15 & 0.238 & 0.249 & 0.281 & 0.342 & 0.279 & 0.021 & n.s. & n.s. & $* *$ & $* *$ & n.s. \\
\hline C18:1C9 & 28.5 & 29.7 & 28.7 & 31.3 & 31.9 & 1.21 & $T$ & n.s. & n.s. & n.s. & n.s. \\
\hline C18:1C15 & 0.048 & 0.031 & 0.015 & 0.047 & 0.078 & 0.016 & * & n.s. & n.s. & n.s. & n.s. \\
\hline C18:2 t11C15 & 0.109 & 0.112 & 0.148 & 0.118 & 0.116 & 0.024 & n.s. & n.s. & n.s. & n.s. & n.s. \\
\hline C18:2 n-6 & 4.88 & 4.15 & 4.29 & 3.60 & 4.95 & 0.426 & n.s. & n.s. & * & n.s. & n.s. \\
\hline CLAC9t11 & 0.595 & 0.544 & 0.544 & 0.301 & 0.532 & 0.078 & n.s. & n.s. & * & * & n.s. \\
\hline CLAt10c12 & 0.038 & 0.035 & 0.036 & 0.019 & 0.022 & 0.005 & $T$ & n.s. & $* *$ & $* *$ & n.s. \\
\hline CLACC & 0.029 & 0.035 & 0.035 & 0.040 & 0.026 & 0.004 & $\mathrm{~T}$ & n.s. & $\mathrm{T}$ & n.s. & n.s. \\
\hline CLAtt & 0.025 & 0.035 & 0.035 & 0.031 & 0.030 & 0.004 & n.s. & $\mathrm{T}$ & n.s. & n.s. & n.s. \\
\hline C18:3c9t11c15 & 0.039 & 0.038 & 0.042 & 0.029 & 0.039 & 0.005 & n.s. & n.s. & n.s. & $\mathrm{T}$ & n.s. \\
\hline C18:3 n-3 & 1.53 & 1.62 & 1.82 & 1.62 & 1.57 & 0.151 & n.s. & n.s. & n.s. & n.s. & n.s. \\
\hline$C 20: 4 n-6$ & 2.70 & 1.90 & 1.78 & 1.70 & 1.46 & 0.429 & n.s. & n.s. & n.s. & n.s. & n.s. \\
\hline$C 20: 5 n-3$ & 1.08 & 0.867 & 0.840 & 0.826 & 0.655 & 0.170 & n.s. & n.s. & n.s. & n.s. & n.s. \\
\hline$C 22: 5 n-3$ & 1.31 & 1.02 & 1.03 & 0.941 & 0.756 & 0.185 & n.s. & n.s. & n.s. & n.s. & n.s. \\
\hline$C 22: 6 n-3$ & 0.272 & 0.245 & 0.252 & 0.273 & 0.233 & 0.035 & n.s. & n.s. & n.s. & n.s. & n.s. \\
\hline Total OBCFA ${ }^{\ddagger}$ & 5.90 & 5.09 & 4.93 & 4.45 & 4.26 & 0.390 & $\mathrm{~T}$ & $\mathrm{~T}$ & $*$ & n.s. & n.s. \\
\hline Total SFA & 43.9 & 45.9 & 45.3 & 46.1 & 45.5 & 1.16 & n.s. & n.s. & n.s. & n.s & n.s. \\
\hline Total MUFA & 34.0 & 35.1 & 34.4 & 36.4 & 37.2 & 1.13 & $T$ & n.s. & n.s. & n.s. & n.s. \\
\hline Total PUFA ${ }^{\ddagger}$ & 13.8 & 11.6 & 11.9 & 10.6 & 11.3 & 1.37 & n.s. & n.s. & n.s. & n.s. & n.s. \\
\hline$n-6 / n-3$ & 1.98 & $1.79 \mathrm{~b}$ & 1.70 & 1.63 & 2.16 & 0.083 & $* * *$ & * & $* *$ & n.s. & n.s. \\
\hline $\mathrm{P} / \mathrm{S}^{\ddagger}$ & 0.167 & 0.136 & 0.148 & 0.122 & 0.152 & 0.019 & n.s. & n.s. & $\mathrm{T}$ & n.s. & n.s. \\
\hline \multicolumn{12}{|c|}{$\begin{array}{l}\text { Indices for elongation and desaturation } \\
\text { activity (calculated as ratios of FA) }\end{array}$} \\
\hline$C 20: 4 n-6 / C 18: 2 n-6$ & 0.518 & 0.449 & 0.410 & 0.469 & 0.296 & 0.055 & * & n.s. & n.s. & n.s. & n.s. \\
\hline$C 20: 5 n-3 / C 18: 3 n-3$ & 0.702 & 0.525 & 0.448 & 0.489 & 0.416 & 0.083 & n.s. & * & $\mathrm{T}$ & n.s. & n.s. \\
\hline$C 22: 5 n-3 / C 18: 3 n-3$ & 0.868 & 0.628 & 0.557 & 0.570 & 0.489 & 0.102 & n.s. & * & * & n.s. & n.s. \\
\hline$C 22: 6 n-3 / C 18: 3 n-3$ & 0.178 & 0.151 & 0.144 & 0.166 & 0.149 & 0.017 & n.s. & n.s. & n.s. & n.s. & n.s. \\
\hline$C 22: 5 n-3 / C 20: 5 n-3$ & 1.25 & 1.21 & 1.26 & 1.19 & 1.20 & 0.068 & n.s. & n.s. & n.s. & n.s. & n.s. \\
\hline$C 22: 6 n-3 / C 20: 5 n-3$ & 0.274 & 0.300 & 0.331 & 0.349 & 0.359 & 0.029 & n.s. & n.s. & n.s. & n.s. & n.s. \\
\hline$C 22: 6 n-3 / C 22: 5 n-3$ & 0.221 & 0.246 & 0.261 & 0.293 & 0.308 & 0.021 & * & n.s. & n.s. & n.s. & n.s. \\
\hline
\end{tabular}

Abbreviations are: FA: fatty acid; FAME: FA methylesters; BDS = botanically diverse silage; WCS = white clover silage; RCS = red clover silage; IRS = intensive English ryegrass silage; $M S L=$ crushed linseed and maize silage; s.e.: standard error; OBFCA: odd- and branched-chain fatty acid; SFA: saturated fatty acid; MUFA $=$ monounsaturated fatty acid; PUFA $=$ polyunsaturated fatty acid.

${ }^{\dagger} \mathrm{T}=$ trend $(0.1<P<0.05) ;{ }^{*}=0.05<P<0.01 ;{ }^{* *}=0.01<P<0.001 ;{ }^{* *}=P<0.001 ;$ n.s. $=$ non-significant; 1 = Orthogonal contrast linseed $v$. forages; $2=$ orthogonal contrast BDS $v$. clover diets; $3=$ orthogonal contrast BDS $v$. IRS; $4=$ orthogonal contrast clover diets $v$. IRS; $5=$ orthogonal contrast WCS $v$. RCS. ${ }^{\ddagger}$ Total OBCFA = sum of all odd- and branched-chain fatty acids: C13:0 iso; C13:0 anteiso; C13:0; C14:0 iso; C15:0 iso; C15:0 anteiso; C15:0; C16:0 iso; C17:0 iso: C17:0 anteiso; C17:0; C17:1 C9. Total SFA = sum of saturated fatty acids: C10:0, C12:0, C13:0, C14:0, C15:0, C16:0, C17:0, C18:0, C20:0 and C22:0.

Total MUFA = sum of monounsaturated fatty acids: C14:1 c9, C15:1 C9, C16:1 t9, C16:1 c9, C17:1 c9, C18:1 t6-t8, C18:1 t9, C18:1 t10, C18:1 t11, C18:1

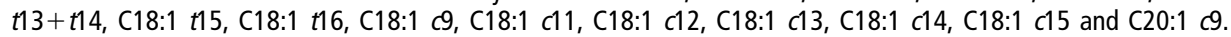

Total PUFA = sum of polyunsaturated fatty acids: C18:2 c9c12, C18:2 t9t12, C18:2 t11c15, C18:2 n-6, C18:3 n-6, C18:3 n-3, CLA c9t11, CLA t10c12, CLA cC, CLA tt, C18:3 c9t11c15, C20:3 n-6, C20:3 n-3, C20:4 n-6, C20:5 n-3, C22:4 n-6, C22:5 n-3 and C22:6 n-3.

$n-6 / n-3$ ratio $=$ ratio between the sum of $C 18: 2 n-6, C 18: 3 n-6, C 20: 3 n-6, C 20: 4 n-6$ and $C 22: 4 n-6$, and the sum of $C 18: 3 n-3, C 20: 3 n-3, C 20: 5 n-3, C 22: 5$ $n-3$ and $C 22: 6 n-3$. P/S ratio = ratio between the sum of $C 18: 2 n-6$ and $C 18: 3 n-3$, and the sum of $C 14: 0, C 16: 0$ and $C 18: 0$

\section{Discussion}

Rumen fermentation patterns within the four groups fed forage silages were similar. Nevertheless, higher proportions of biohydrogenation intermediates, in particular CLA c9t11 and C18:1 t11 were found in the rumen of BDS animals, despite the similar precursor proportions for the different silages (except for the IRS which presented a higher feed C18:2 n-6+C18:3 n-3 proportion). Microbial markers such as rumen OBCFA (Vlaeminck et al., 2005) 


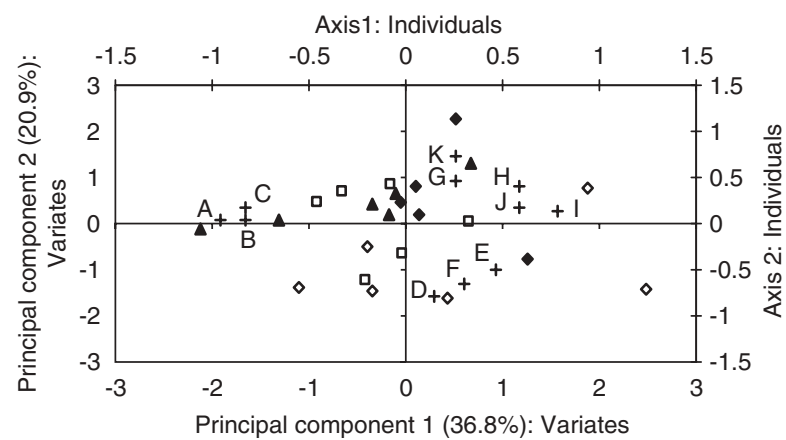

Figure 1 Biplot representing both regression factor scores according to the silage groups (botanically diverse silage $(\diamond)$, white clover silage $(\square)$, red clover silage $(\boldsymbol{\Lambda})$, intensive ryegrass silage $(\boldsymbol{\bullet}))$ and loadings $(+)$ of the first two principal components, based on proportions (\% of odd- and branched-chain FA (OBCFA)) of rumen OBCFA. The letters refer to individual OBCFA: A - C15:0; $\mathrm{B}$ - anteiso C13:0; $\mathrm{C}$ - iso C14:0; $\mathrm{D}$ - iso $\mathrm{C} 16: 0 ; \mathrm{E}$ - iso $\mathrm{C} 15: 0 ; \mathrm{F}$ - iso $\mathrm{C} 13: 0 ; \mathrm{G}-\mathrm{C} 17: 1 ; \mathrm{H}$ - anteiso $\mathrm{C} 15: 0 ; \mathrm{I}$ anteiso C17:0; J - C13:0; K - C17:0.

could suggest a different microbial population for the BDS animals. Vlaeminck et al. (2006), observed a positive correlation between iso $\mathrm{C} 17: 0$ and $\mathrm{C} 18: 1 \mathrm{t11}$, from which they suggested group B bacteria, responsible for the final hydrogenation step, having lower iso C17:0 proportions. Further and similar to the results of Lourenço et al. (2007), reporting higher rumen iso $\mathrm{C17:0}$ proportions in the rumen of $B D$ animals, increased proportions of C16:1 t9+ iso C17:0 were observed in the rumen contents of BDS animals (Table 3). In addition, a PCA analysis (Figure 1) to determine the components which account for most of the variation in OBCFA, revealed a negative score on the second principal component for the BDS animals compared with animals fed the other forage diets (WCS, RCS and IRS), supporting the suggestion of a different microbial population for the BDS animals, based on the proportions of OBCFA observed in the rumen contents of the animals. The suggested different microbial population in the rumen of BDS animals may explain the changes observed in the rumen biohydrogenation intermediates. These suggested differences in microbial population and consequent differences in accumulation of some biohydrogenation intermediates may be due to the presence of compounds in the BDS plant species, which might have antimicrobial activity (Wallace, 2004) and affect rumen fermentation pattern (Busquet et al., 2006).

Comparing the forages $v$. linseed feeding, it was clear that rumen contents of MSL animals had the highest C18:1 $t 10$ proportions. These higher proportions of C18:1 t10 were not associated with a lower rumen $\mathrm{pH}$ for the MSL animals, as described by Loor et al. (2003 and 2005). Moreover, these animals showed a different fermentation pattern in terms of increased propionate and lower acetate proportions when compared with the other four diets. This pattern was most probably due to the higher starch content of maize (increase of propionate at the expense of acetate, typical for starch-rich concentrate diets (France and Siddons, 1993)). Additionally, the supplementation of PUFA through

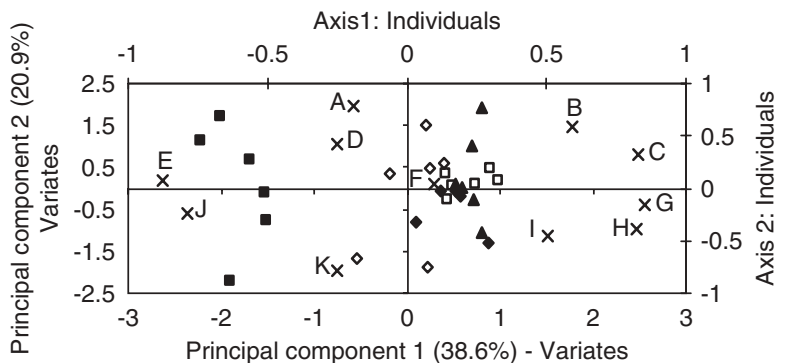

Figure 2 Biplot representing both regression factor scores according to the silage groups (botanically diverse silage $(\diamond)$, white clover silage $(\square)$, red clover silage $(\boldsymbol{\Delta})$, intensive ryegrass silage $(\bullet)$, maize silage and linseed $(\boldsymbol{\square})$ ) and loadings $(X)$ of the first two principal components, based on proportions ( $\%$ of odd- and branched-chain FA (OBCFA)) of rumen OBCFA. The letters refer to individual OBCFA: $A-C 15: 0 ; B-$ anteiso $\mathrm{C13:0;} \mathrm{C}$ - iso C14:0; D - iso C16:0; $\mathrm{E}$ - iso C15:0; $\mathrm{F}$ - iso $\mathrm{C} 13: 0$ G - C17:1; H - anteiso C15:0; I - anteiso C17:0; J - C13:0; K - C17:0.

linseed might also have a methane depressive effect, resulting in a shift of the VFA pattern towards increased propionate proportions (Chilliard et al., 2000; Owens et al., 2006). Moreover, shifts towards a more amylolytic population could also be suggested from changes in rumen OBCFA, in particular decreases of iso C14:0 (Table 3). This FA has also been reported to be negatively correlated with C18:1 t10 by Vlaeminck et al. (2006), who suggested hydrogenating bacteria responsible for the appearance of C18:1 t10 in the rumen to have low proportions of iso C14:0. The suggestion for a different microbial population associated with the MSL diet is further illustrated by the PCA biplot (Figure 2), which revealed the lowest first principal component score for the MSL animals compared with the other four groups, with the MSL animals clustering together, based on the proportions of OBCFA observed in the rumen contents of the animals. The different bacterial populations in rumen contents of MSL group could be responsible for the shift of the hydrogenation of C18:2 n-6 from CLA $c 9 t 11$ and C18:1 t11 to CLA $t 10 c 12$ and C18:1 t10. Additionally, the higher proportions of C18:1 110 could arise from the isomerisation of $\mathrm{C} 18: 1 \mathrm{t11}$ or other C18:1 trans-isomers (Proell et al., 2002; Loor et al., 2005) or from the isomerisation of C18:1 c9 (Mosley et al., 2002; Loor et al., 2005).

Another important finding in this study was the higher C18:3n-3 proportion in the rumen contents of MSL animals, despite the similar supply of C18 PUFA from the MSL diet compared with the other forage diets (Table 2). This might be due to the presence of C18:3 n-3 in triacylglycerols in crushed linseed whereas the majority of FA in silages are unesterified. Indeed, Lourenço et al. (2005a) reported 51\% of the silage FA to be in the unesterified form. Additionally, C18:3 $n-3$ might have been physically protected against microbial attack by the coating of the linseed, which might be effective in impeding the access of the microbial lipases to the C18:3 n-3. Moreover, rumen contents of RCS animals also had significantly higher proportions of $\mathrm{C} 18: 3 \mathrm{n}-3$ compared with the rumen contents of WCS animals. RCSs have been described to increase omega-3 FA in milk of 


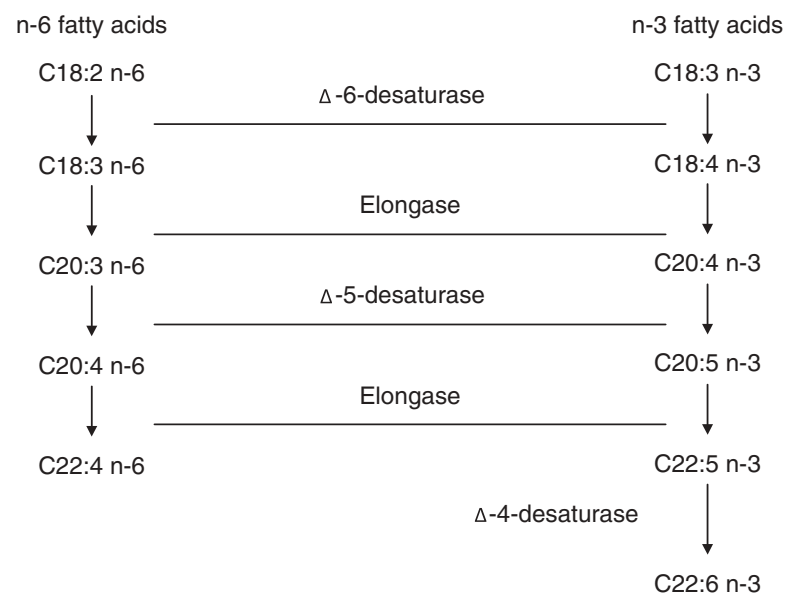

Figure 3 Conversion of $\mathrm{C} 18: 2 \mathrm{n}-6$ and $\mathrm{C} 18: 3 \mathrm{n}-3$ into their long-chain fatty acid products (adapted from Raes et al. (2004a)).

cows fed silages (Dewhurst et al., 2003b). This has been hypothesised to be related to higher proportions of esterified FA being protected by the denaturation of plant lipases or to o-quinones (produced by polyphenol oxidase (PPO) activity (Jones et al., 1995)) linkages to nucleophilic amino acids of enzymes, e.g. lipases (Lee et al., 2004).

IM fat is known to be less responsive than SC fat to changes in the dietary supply of FA or changes in FA rumen metabolism (Demirel et al., 2004). In this study, FA profile of the SC fat of the animals was a reflection of the rumen data and was more responsive to the changes observed in the rumen FA metabolism than the IM fat. IM fat of BDS animals had the highest, however not significantly different, proportions of most PUFA in line with former studies on pastured lambs (Ådnøy et al., 2005; Lourenço et al., 2007). Although proportions of $\mathrm{C} 20: 4 \mathrm{n}-6, \mathrm{C} 20: 5 \mathrm{n}-3, \mathrm{C} 22: 5 \mathrm{n}-3$ and C22:6 n-3 did not differ between groups, indices for desaturation and elongation activity did, suggesting that tissue FA metabolism may be influenced by feeding BDSs, similar to the results of Lourenço et al. (2007). Moreover, results suggest that the activity of $\Delta 6$-desaturase, elongase and $\Delta 5$-desaturase (Figure 3 ) might be affected as BDS animals had higher C20:5 n-3/C18:3 n-3 and C22:5 n-3/ C18:3 $n-3$ indices than the IRS animals, and a higher C20:4 $n-6 / C 18: 2 n-6$ indices than the WCS and RCS animals. The indices representing the last steps of elongation and desaturation of long-chain FA (Figure 3) in muscle of BDS animals did not differ from WCS, RCS and IRS animals (C22:6n-3/C18:3 n-3, C22:5 n-3/C20:5n-3, C22:6n-3/ C20:5n-3 and C22:6n-3/C22:5n-3 indices). This could be due to a negative feed-back of the product FA, limiting this last step of elongation and desaturation of long-chain FA (Raes et al., 2004a). Nevertheless, a confounding effect with the lower IM fat content of these animals and associated higher phospholipid/triacylglycerol ratios and longchain PUFA proportion cannot be excluded.

This study suggested that feeding different silages induced changes in the rumen FA metabolism which might be related to differences observed in the extent of rumen biohydrogenation of PUFA. The higher rumen C18:3 n-3 concentrations of linseed supplemented animals might be related to its presence in triacylglycerol and a possible physical protection against microbial lipases through the seed coating. Additionally, higher proportions of C18:3n-3 in the rumen contents of RCS animals were hypothesised to be due to the action of its PPO enzyme. Finally, feeding silages from more botanically diverse pastures could affect tissue FA metabolism as suggested from the indices for desaturation and elongation of PUFA. Overall, these results suggest that animals consuming more BDSs offer opportunities to produce a healthier FA profile from a human health perspective.

\section{Acknowledgements}

M. Lourenço acknowledges receipt of a PhD grant from Foundation for Science and Technology - Portugal. Financial support for this experiment is by IWT - Institute for the Promotion of Innovation by Science and Technology in Flanders. Technical assistance of Sabine Coolsaet, Erik Claeys and Stefaan Lescouhier is thankfully acknowledged. We thank Ludo Van Alphen for providing the lambs and the botanically diverse, white clover and red clover silages.

\section{References}

Ådnøy T, Haug A, Sørheim 0, Thomassen MS, Varszegi Z and Eik LO 2005. Grazing on mountain pastures - does it affect meat quality in lambs? Livestock Production Science 94, 25-31.

Busquet M, Calsamiglia S, Ferret A and Kamel C 2006. Plant extracts affect in vitro rumen microbial fermentation. Journal of Dairy Science 89, 761-771.

Centraal Veevoederbureau 2004. Table booklet animal nutrition 2004. [Feed requirements of farm animals and nutritional value characteristics.] Central Bureau for Livestock Feeding, Lelystad, pp. 110.

Chilliard Y, Ferlay A, Mansbridge M and Doreau M 2000. Ruminant milk fat plasticity: nutritional control of saturated, polyunsaturated, trans and conjugated fatty acids. Annales de Zootechnie 49, 181-205.

Chow TT, Fievez V, Moloney AP, Raes K, Demeyer D and De Smet S 2004. Effect of fish oil on in vitro rumen lipolysis, apparent biohydrogenation of linoleic acid and linolenic acid and accumulation of biohydrogenation intermediates. Animal Feed Science and Technology 117, 1-12.

Collomb M, Bütikofer U, Siebe R, Jeangros B and Bosset J0 2002. Composition of fatty acids in cow's milk fat produced in the lowlands, mountains and highlands of Switzerland using high-resolution gas chromatography. International Dairy Journal 12, 649-659.

Demirel G, Wachira AM, Sinclair LA, Wilkinson RG, Wood JD and Enser M 2004. Effects of dietary n-3 polyunsaturated fatty acids, breed and dietary vitamin $\mathrm{E}$ on the fatty acids of lamb muscle, liver and adipose tissue. British Journal of Nutrition 91, 551-565.

Dewhurst RJ, Evans RT, Scollan ND, Moorby JM, Merry RJ and Wilkins RJ 2003a. Comparison of grass and legume silages for milk production. 2. In vivo and in sacco evaluations of rumen function. Journal of Dairy Science 86, 2612-2621.

Dewhurst RJ, Fisher WJ, Tweed JKS and Wilkins RJ 2003b. Comparison of grass and legume silages for milk production. 1. Production responses with different levels of concentrate. Journal of Dairy Science 86, 2598-2611.

European Community 1993. Determination of crude proteinDirective no. L179/ 9 of the Commission of the European Communities of 22.07.93. Official Journal European Community, Brussels.

France J and Siddons RC 1993. Volatile fatty acid production. In:Quantitative aspects of ruminants digestion and metabolism (ed. JM Forbes and J France), pp. 107-121. CAB International, Wallingford. 
International Organisation for Standardisation 1973. ISO-1443 - the Soxhlet method. Geneva, Switzerland.

Jones BA, Hatfield RD and Muck RE 1995. Screening legume forages for soluble phenols, polyphenol oxidase and extract browning. Journal of the Science of Food and Agriculture 67, 109-112.

Lee MRF, Harris LJ, Dewhurst RJ, Merry RJ and Scollan ND 2003. The effect of clover silages on long chain fatty acid rumen transformations and digestion in beef steers. Animal Science 76, 491-501.

Lee MRF, Winters AL, Scollan ND, Dewhurst RJ, Theodorou MK and Minchin FR 2004. Plant-mediated lipolysis and proteolysis in red clover with different polyphenol oxidase activities. Journal of the Science of Food and Agriculture 84, 1639-1645.

Loor JJ, Hoover WH, Miller-Webster TK, Herbein JH and Polan CE 2003. Biohydrogenation of unsaturated fatty acids in continuous culture fermenters during digestion of orchardgrass or red clover with three levels of ground corn supplementation. Journal of Animal Science 81, 1611-1627.

Loor JJ, Ueda K, Ferlay A, Chilliard Y and Doreau M 2005. Intestinal flow and digestibility of trans fatty acids and conjugated linoleic acids (CLA) in dairy cows fed a high-concentrate diet supplemented with fish oil, linseed oil or sunflower oil. Animal Feed Science and Technology 119, 203-225.

Lourenço M, Van Ranst G and Fievez V 2005a. Differences in extent of lipolysis in red or white clover and ryegrass silages in relation to polyphenol oxidase activity. Communications in Agricultural and Applied Biological Sciences 70, 169-172.

Lourenço M, Vlaeminck B, Bruinenberg M, Demeyer D and Fievez V 2005b. Milk fatty acid composition and associated rumen lipolysis and fatty acid hydrogenation when feeding forages from intensively managed or seminatural grasslands. Animal Research 54, 471-484.

Lourenço M, Van Ranst G, De Smet S, Raes K and Fievez V 2007. Effect of grazing pastures with different botanical composition by lambs on rumen fatty acid metabolism and fatty acid pattern of longissimus muscle and subcutaneous fat. Animal 1, 537-545.

Mosley EE, Powell GL, Riley MB and Jenkins TC 2002. Microbial biohydrogenation of oleic acid to trans isomers in vitro. Journal of Lipid Research 43, 290-296.

Owens D, McGee M, O'Kiely P and O'Mara F 2006. Intake, rumen fermentation and plasma metabolites in beef cattle offered grass silage, maize silage, fermented whole crop wheat and alkalage. Proceedings of the British Society of Animal Science, 2006, p. 133.
Proell JM, Mosley EE, Powell GL and Jenkins TC 2002. Isomerization of stable isotopically labelled elaidic acid to cis and trans monoenes by ruminal microbes. Journal of Lipid Research 43, 2072-2076.

Raes K, De Smet S and Demeyer D 2001. Effect of double-muscling in BelgianBlue young bulls on the intramuscular fatty acid composition with emphasis on conjugated linoleic acid and polyunsaturated fatty acids. Animal Science 73, 253-260.

Raes K, De Smet S and Demeyer D 2004a. Effect of dietary fatty acids on incorporation of long chain polyunsaturated fatty acids and conjugated linoleic acid in lamb, beef and pork meat: a review. Animal Feed Science and Technology 113, 199-221.

Raes K, Haak L, Balcaen A, Claeys E, Demeyer D and De Smet S 2004b. Effect of linseed feeding at similar linoleic acid levels on the fatty acid composition of double-muscled Belgian-Blue young bulls. Meat Science 66, 307-315.

Statistical Packages for the Social Sciences 2003. SPSS software for Windows, release 12.0, SPSS Inc., Chicago, IL, USA.

Tamminga S Van Straalen WM, Subnel APJ, Meijer RGM, Steg A, Wever CJG and Blok MC 1994. The Dutch protein evaluation system - the DVE/OEBsystem. Livestock Production Science 40, 139-155.

Van Es AJH 1978. Feed evaluation for ruminants. I. The system in use from May 1977 onwards in The Netherlands. Livestock Production Science 5, 331-345.

Van Nevel CJ and Demeyer DI 1977. Effect of monesin on rumen metabolism in vitro. Applied Environment Microbiology 34, 251-257.

Van Soest PJ, Robertson JB and Lewis BA 1991. Methods for dietary fibre, neutral detergent fibre and nonstarch polysaccharides in relation to animal nutrition. Journal of Dairy Science 74, 3583-3597.

Vlaeminck B, Dufour C, Van Vuuren AM, Cabrita AMR, Dewhurst RJ, Demeyer $D$ and Fievez V 2005. Potential of odd and branched chain fatty acids as microbial markers: evaluation in rumen contents and milk. Journal of Dairy Science 88, 1031-1041.

Vlaeminck B, Fievez V, Cabrita ARJ, Fonseca AJM and Dewhurst RJ. 2006. Factors affecting odd and branched chain fatty acids in milk: a review. Animal Feed Science and Technology 131, 389-417.

Wallace RJ 2004. Antimicrobial properties of plant secondary metabolites. Proceedings of the Nutrition Society 63, 621-629.

Žan M, Stibilj V and Rogelj I 2006. Milk fatty acid composition of goats grazing on alpine pasture. Small Ruminant Research 64, 45-52. 